\title{
CORRECTION
}

View Article Online

View Journal I View Issue

(1) CrossMark

Cite this: RSC Adv., 2016, 6, 68592

\section{Correction: The equilibrium and dynamic surface tension of polymeric surfactants based on epoxidized soybean oil grafted hydroxyethyl cellulose}

\author{
Xujuan Huang, ${ }^{\text {ab }} \mathrm{He} \mathrm{Liu}^{\text {*a }}{ }^{\mathrm{a}}$ Shibin Shang, ${ }^{\text {*a }}$ Zhaosheng Cai ${ }^{\mathrm{b}}$ and Jie Song ${ }^{\mathrm{c}}$
}

DOI: $10.1039 / c 6 r a 90059 c$

www.rsc.org/advances

Correction for 'The equilibrium and dynamic surface tension of polymeric surfactants based on epoxidized soybean oil grafted hydroxyethyl cellulose' by Xujuan Huang et al., RSC Adv., 2016, 6, 64121-64128.

In the original manuscript, the structure of the epoxidized soybean oil modified hydroxyethyl cellulose polymeric surfactant $(\mathrm{H}-$ ESO-HEC) in Fig. 1 was wrongly drawn. The corrected Fig. 1 appears below.

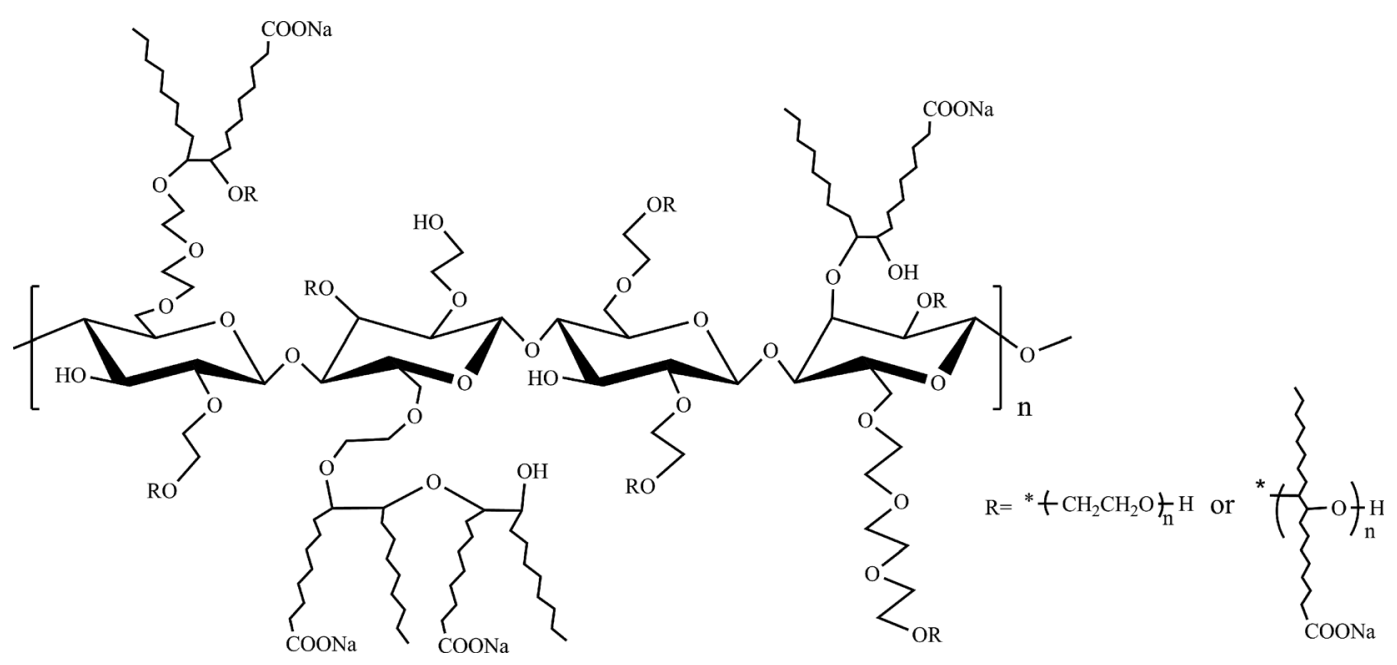

Fig. 1 Structure of epoxidized soybean oil modified hydroxyethyl cellulose polymeric surfactant.

The Royal Society of Chemistry apologises for these errors and any consequent inconvenience to authors and readers.

${ }^{a}$ Institute of Chemical Industry of Forestry Products, Chinese Academy of Forestry, Key Laboratory of Biomass Energy and Material, National Engineering Laboratory for Biomass Chemical Utilization, Key and Laboratory on Forest Chemical Engineering, State Forestry Administration, Nanjing, Jiangsu Province, 210042 China. E-mail: liuheicifp@hotmail. com; shangsb@hotmail.com

${ }^{b}$ School of Chemical and Biological Engineering, Yancheng Institute of Technology, Yancheng 224051, Jiangsu Province, China

'Department of Chemistry and Biochemistry, University of Michigan-Flint, Flint, Michigan 48502, USA 